Check for updates

Cite this: RSC Adv., 2018, 8, 3982

Received 18th October 2017 Accepted 12th January 2018

DOI: $10.1039 / c 7 r a 11487 g$

rsc.li/rsc-advances

\title{
Highly selective fluorescent carbon dots probe for mercury(II) based on thymine-mercury(II)-thymine structure $\uparrow$
}

\begin{abstract}
Yong Li, Zhan-Yao Zhang, Hao-Fan Yang, Guang Shao and Feng Gan (D)*
A novel thymine-functional fluorescent sensor was developed for $\mathrm{Hg}^{2+}$ detection with high sensitivity and selectivity. The synthesis of the fluorescent sensor took two steps (1) the synthesis of amine-functionalized carbon dots (CDs-PEI); and (2) the attaching of thymine moieties on to the surface of the CDs-PEI through EDC/NHS coupling chemistry to obtain the thymine-functional fluorescence carbon dots (CDs-Thy). The CDs-Thy were successfully applied to detect $\mathrm{Hg}^{2+}$ by quenching fluorescence with a rapid response through photoinduced electron transfer with the formation of $\mathrm{T}-\mathrm{Hg}^{2+}-\mathrm{T}$ structures. The linear concentration range of $\mathrm{Hg}^{2+}$ is $0-1.0 \mu \mathrm{mol} \mathrm{L} \mathrm{L}^{-1}$ and a limit of detection (LOD) as low as $3.5 \times$ $10^{-8} \mathrm{~mol} \mathrm{~L}^{-1}$ was obtained. Moreover, the CDs-Thy can resist interference from other metal ions and anions. The CDs-Thy were also used for the $\mathrm{Hg}^{2+}$ detection in water samples and the recoveries were from $90 \%$ to $104 \%$. Due to the simplicity and effectiveness, it shows great promise as a potential sensing platform for $\mathrm{Hg}^{2+}$.
\end{abstract}

\section{Introduction}

Mercury(II) is a toxic pollutant that is widely distributed in soil, water, and air. ${ }^{1}$ Metal smelting, coal production, waste disposal, refining and manufacturing, and the production of chlor-alkali processes will discharge large quantities of mercury into the environment. ${ }^{2-4}$ Inorganic mercury can be transformed into the highly toxic form such as organic methylmercury under the catalysis of microorganism. These organic mercury that can amass in human body throughout the food $w^{2,2,5,6}$ and cause cinesipathy, disgnosia, cerebral lesion, impaired vision, and even death. ${ }^{7-9}$ For these reasons, the development of straightforward, highly sensitive and selective methods for monitoring and detecting $\mathrm{Hg}^{2+}$ is of great importance.

In recent years, fluorescent probes for $\mathrm{Hg}^{2+}$ detection have attracted extensive attention due to their convenient and timeefficient procedures, ${ }^{\mathbf{1 0}-16}$ which make them good alternatives to traditional analytical techniques, such as electrochemical method, ${ }^{17}$ atomic absorption spectroscopy (AAS), ${ }^{18}$ and inductively coupled plasma mass spectrometry (ICP-MS), ${ }^{19,20}$ etc. Another alternative could be the photoluminescent carbon dots (CDs) because of their obvious advantages such as easy in

School of Chemistry, Sun Yat-Sen University, Guangzhou 510275, P. R. China. E-mail: cesgf@mail.sysu.edu.cn; Fax: +86 208411 0918; Tel: +862084110918

$\dagger$ Electronic supplementary information (ESI) available: Standard curve to calculate the modification amounts of thymine derivative (Fig. S1). Conditions optimization of $\mathrm{pH}$ and reaction time (Fig. S2). Linear plots of the fluorescence intensities of CDs-Thy with the addition of $\mathrm{Hg}^{2+}$ (Fig. S3). See DOI: $10.1039 / \mathrm{c} 7 \mathrm{ra11487g}$ preparation, ${ }^{21}$ environmental friendliness, ${ }^{22}$ good biocompatibility, ${ }^{23}$ water solubility ${ }^{24}$ and low toxicity ${ }^{25}$ by comparing with metal quantum dots and traditional organic dyes. ${ }^{26}$ They have also been applied to the analysis and detection of ions and biomolecules. ${ }^{21,27-32}$ However, in their recent status, the photoluminescent CDs showed low sensitivity and poor selectivity. ${ }^{33-36}$ Therefore, it remains a challenge to develop fluorescent CDs for highly selective and sensitive recognition of $\mathrm{Hg}^{2+}$ in biological and aqueous systems.

In this work, we developed a new kind of fluorescent CDs for $\mathrm{Hg}^{2+}$ detection. We redesigned the functional surfaces of existing photoluminescent $\mathrm{CDs}^{37}$ that had found application in $\mathrm{Cu}^{2+}$ detection ${ }^{38}$ with commendable selectivity. We found that there are amino groups on the surface of the CDs, which can be modified by thymine ( $\mathrm{T})$. As the thymine can form $\mathrm{T}-\mathrm{Hg}^{2+}-\mathrm{T}$ structure (Fig. 1A), ${ }^{39,40}$ we conjectured that the newly developed thymine-functional CDs (CDs-Thy) will have high selectivity for $\mathrm{Hg}^{2+}$. The results showed that the CDs-Thy can be applied to determine the $\mathrm{Hg}^{2+}$ in water samples. Satisfactory results were obtained.

\section{Experimental}

\subsection{Reagents}

Citric acid (CA), 1-ethyl-3-(3-dimethylaminopropyl) carbodiimide (EDC), polyethyleneimine (PEI, M.W. 1800) and $N$-hydroxy-succinimide (NHS) were obtained from Aladdin (Shanghai, China). 2-( $N$-Morpholino)ethanesulfonic acid (MES) and thymine-1-acetic acid were purchased from Shanghai Macklin Biochemical Co. Ltd. (Shanghai, China). $\mathrm{Hg}^{2+}$ standard 
A

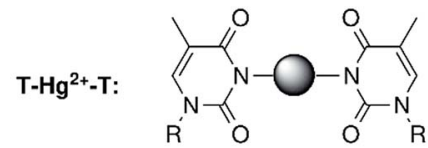

B<smiles>NC1[C@H](N)C(N)[C@H](N)[C@H](N)C(N)[C@H]1N</smiles><smiles>Nc1ccccc1</smiles>

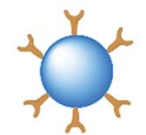

CDs-PEI
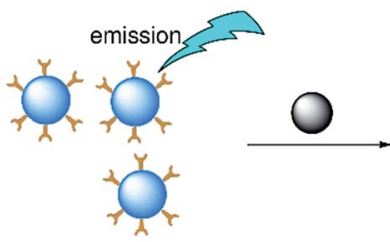

Q $: \mathrm{Hg}^{2+}$

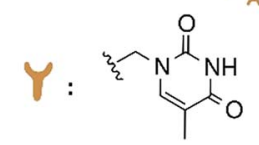

Fig. 1 (A) The metal ion-mediated base pairs of $\mathrm{T}-\mathrm{Hg}^{2+}-\mathrm{T}$. (B) Synthetic route of CDs-Thy. (C) Schematic illustration of the CDs-Thy for $\mathrm{Hg}^{2+}$ selective recognition.

solution $\left(100 \mu \mathrm{g} \mathrm{mL} \mathrm{m}^{-1}, 5 \% \mathrm{HNO}_{3}\right)$ was purchased from Macklin Biochemical Co. Ltd. (Shanghai, China). Other cationic salts were obtained from Guangzhou Chemical Regent Factory (Guangzhou, China).

\subsection{Instruments}

The UV-visible absorption and the FT-IR spectra were scanned using UV 3150 UV-vis spectrometer (Shimadzu) and IR-Nicolet Avatar 330 spectrometer (Bruker), respectively. The fluorescence measurements and quantum yields were carried out by using a RF5301 spectrometer (Shimadzu). A PHS-25 pH meter (INESA Scientific Instrument Co., Ltd) was employed to determine $\mathrm{pH}$ values. The ${ }^{1} \mathrm{H}$ NMR spectra were obtained by using Avance III- $400 \mathrm{MHz}$ spectrometer (Bruker). The transmission electron microscope (TEM) images were measured by using JEM-2010HR (Jeol Ltd). X-ray photoelectron spectroscopy (XPS) and fluorescent lifetime were recorded using an ESCALab250Xi spectroscopy (Thermo Fisher) and FLSP920 photoluminescence spectrometer (Edinburgh Instruments Ltd), respectively.

\subsection{Synthesis of amine-functionalized CDs (CDs-PEI)}

The CDs-PEI were prepared according to published papers elsewhere. ${ }^{37,38}$

\subsection{Synthesis of thymine-functionalized CDs (CDs-Thy)}

The CDs-Thy were synthesized by using excess thymine-1-acetic acid to react with the CDs-PEI. Before the modification of thymine on the CDs-PEI, the thymine-1-acetic acid $(128 \mathrm{mg}$, $0.698 \mathrm{mmol})$ was activated with EDC (161 $\mathrm{mg}, 0.840 \mathrm{mmol})$ and NHS (385.4 mg, $3.35 \mathrm{mmol})$ in $140 \mathrm{~mL}$ MES $(0.1 \mathrm{M}$, pH 5.5) solution for $20 \mathrm{~min}$ at $25{ }^{\circ} \mathrm{C}$ with constant stirring. Then the
CDs-PEI (44.0 mg) were added into the solution and kept reacting for another $48 \mathrm{~h}$ (Fig. 1B). After reaction, the concentrated solution was column chromatographed on silica-gel $(0.01 \mathrm{M} \mathrm{HCl})$ to remove the by-products.

\subsection{Fluorescence measurement}

Stock solution of the CDs-Thy $\left(200 \mu \mathrm{g} \mathrm{mL}^{-1}\right)$ was prepared using deionized water. Stock solutions of cations $(0.001 \mathrm{M})$ were prepared under suitable $\mathrm{pH}$ conditions. The $\mathrm{pH}$ optimization experiments of CDs-Thy in the presence and absence of $\mathrm{Hg}^{2+}$ between 5.8 and 8.2 were obtained through the fluorescence emission intensities, respectively. Real time fluorescent signals of the CDs-Thy were obtained with different concentrations of $\mathrm{Hg}^{2+}$ to optimize the optimal reaction time. All fluorescence spectra were recorded at optimized detection conditions in the PBS buffer solution $(0.1 \mathrm{M}, \mathrm{pH} 7.4)$ at $25^{\circ} \mathrm{C}$.

\subsection{Measurement of water samples}

Tap water and Pearl River water were used for $\mathrm{Hg}^{2+}$ detection. All these samples were centrifuged and filtered with micropore membranes. The obtained filtrate was added with standard $\mathrm{Hg}^{2+}$ samples with different concentrations and used for further analysis.

\section{Results and discussion}

\subsection{Characterization of CD-PEI and CDs-Thy}

To investigate the surface modification of the CDs-Thy, FT-IR spectroscopy was used to characterize the CDs-PEI, thymine-1acetic acid and the CDs-Thy, respectively. As shown in the spectrum a of Fig. 2A, the peaks at $3414 \mathrm{~cm}^{-1}\left(v_{\mathrm{N}-\mathrm{H}}\right)$ and $1630 \mathrm{~cm}^{-1}\left(\delta_{\mathrm{N}-\mathrm{H}}\right)$ confirmed that the surface of CDs-PEI contain amine groups. The presence of these amine groups provides CDs with the potential to be modified with the thymine-1-acetic acid consisting of - $\mathrm{COOH}$ group. Compared to the CDs-PEI, the CDsThy have the characteristic peaks in $2974 \mathrm{~cm}^{-1}\left(v_{-\mathrm{CH}_{3}}\right.$ and $\left.v_{-\mathrm{CH}_{2}}\right)$ and $1479 \mathrm{~cm}^{-1}\left(\delta_{-\mathrm{CH}_{2}}\right)$ as the spectrum b shown in the Fig. $2 \mathrm{~A}$, ascribing to vibration of $-\mathrm{CH}_{3}$ and $-\mathrm{CH}_{2}$, which can also be found at $2961 \mathrm{~cm}^{-1}$ and $1483 \mathrm{~cm}^{-1}$ in the IR spectrum of thymine-1acetic acid as the spectrum c shown in Fig. 2A. In addition, the CDs-Thy show more peaks around $1641 \mathrm{~cm}^{-1}\left(v_{\mathrm{C}=\mathrm{O}}\right)$ and $1268 \mathrm{~cm}^{-1}\left(v_{\mathrm{C}-\mathrm{N}}\right.$ and $\left.\delta_{\mathrm{N}-\mathrm{H}}\right)$ that are all attributed to the thymine-1acetate groups on the surface of CDs-Thy, which also can be found in the IR spectrum of thymine-1-acetic acid at $1633 \mathrm{~cm}^{-1}$ and $1258 \mathrm{~cm}^{-1}$ as the spectrum c of Fig. 2A. These results revealed that the thymine-1-acetic group was modified on to the surface of the CDs. Moreover, with the formation of carbonyl amide, the absence of the amide-II band at $1568 \mathrm{~cm}^{-1}\left(\delta_{\text {-CONH-}}\right)$ can further prove the successful conjugation of the CDs-PEI and the thymine-1-acetic acid.

Fig. 2B shows the ${ }^{1} \mathrm{H}$ NMR spectra of the CDs-Thy, the CDsPEI and the esterified product of thymine-1-acetic acid, respectively. In the ${ }^{1} \mathrm{H}$ NMR spectrum of the CDs-Thy, the multiple peaks at $3.1 \mathrm{ppm}$ corresponded to the resonance signals of alkyl group connected with $\mathrm{N}$ atoms and $\mathrm{C}=\mathrm{O}$. One can also find that the chemistry shifts at $1.8 \mathrm{ppm}, 4.4 \mathrm{ppm}$ and 

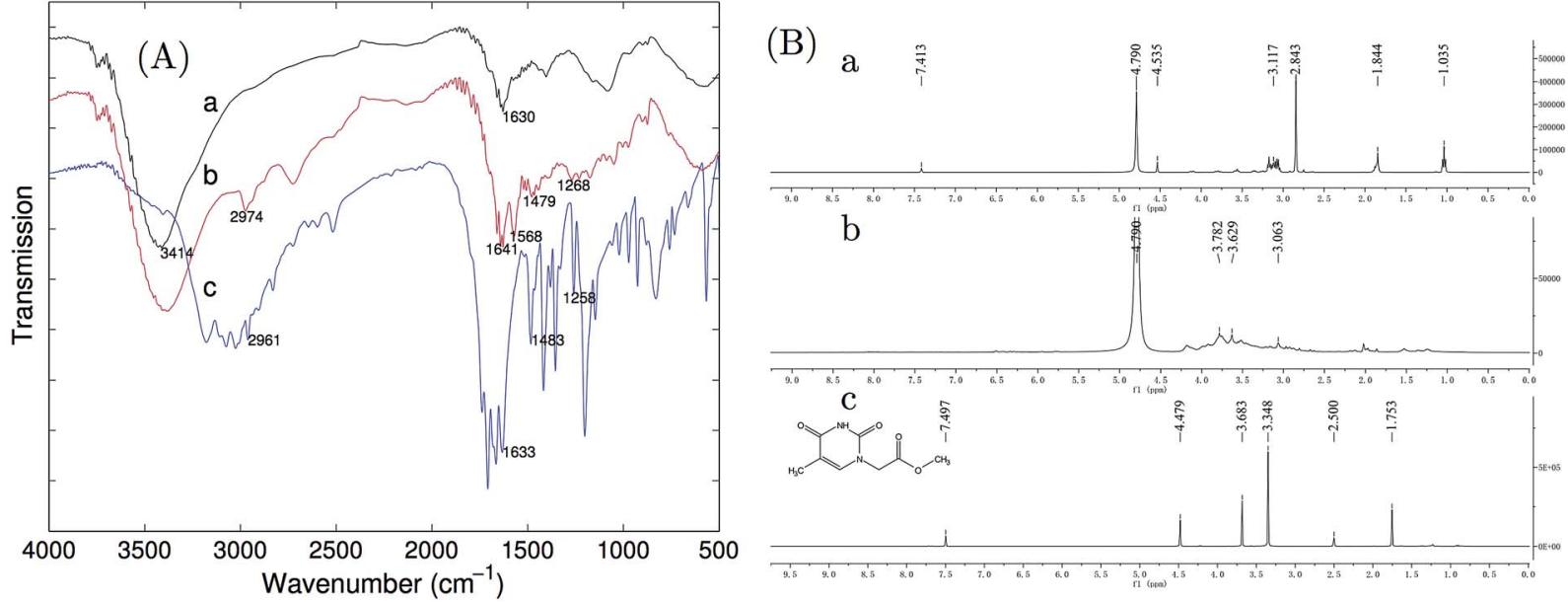

Fig. 2 (A) FT-IR spectra of (a) CDs-PEI, (b) CDs-Thy and (c) thymine-1-acetic acid, respectively. (B) ${ }^{1} \mathrm{H}$ NMR spectra of (a) the CDs-Thy (in $\mathrm{D}_{2} \mathrm{O}$ ), (b) the CDs-PEI (in $\mathrm{D}_{2} \mathrm{O}$ ) and (c) methyl thymine-1-acetate (in DMSO- $d_{6}$ ), respectively.

$7.3 \mathrm{ppm}$ can be attributed to the proton resonance signals of the $-\mathrm{CH}_{3},-\mathrm{CH}_{2}-$ and the alkene in heterocycle of the thymine functional groups, respectively. All the peaks of these protons can also be found in the ${ }^{1} \mathrm{H}$ NMR of CDs-PEI (around $3.7 \mathrm{ppm}$ in b of Fig. 2B) and methyl thymine-1-acetate (1.8 ppm, $4.4 \mathrm{ppm}$ and 7.3 ppm in c of Fig. 2B). The reason to measure the ${ }^{1} \mathrm{H}$ NMR spectrum of methyl thymine-1-acetate instead of that of thymine-1-acetic acid is that the later is not soluble in water. These results confirmed that the CDs-Thy were successfully prepared from the CDs-PEI and thymine derivative.

Fig. 3 shows the XPS spectra of CDs-PEI and CDs-Thy, respectively. Both of the XPS survey spectra of CDs-PEI (Fig. 3a) and CDs-Thy (Fig. 3b) show the peaks at $198.8 \mathrm{eV}$ (Cl 2p), $269.4 \mathrm{eV}$ (Cl 2s), $285.4 \mathrm{eV}$ (C 1s), $400.4 \mathrm{eV}$ (N 1s), and $532.1 \mathrm{eV}$ (O 1s), which can be attributed to $\mathrm{Cl} 2 \mathrm{p}, \mathrm{Cl} 2 \mathrm{~s}, \mathrm{C} 1 \mathrm{~s}, \mathrm{~N}$ $1 \mathrm{~s}$, and $\mathrm{O} 1 \mathrm{~s}$, respectively. The detected chloride was from column chromatography processing. As shown in Fig. 3c, the $\mathrm{C}$ 1s XPS spectrum of the CDs-PEI can be deconvoluted into three carbon states at $284.6 \mathrm{eV}, 286.1 \mathrm{eV}$, and $288.4 \mathrm{eV}$ which are attributed to $\mathrm{C}-\mathrm{C} / \mathrm{C}=\mathrm{C}, \mathrm{C}-\mathrm{O} / \mathrm{C}-\mathrm{N}$ and $\mathrm{O}-\mathrm{C}=\mathrm{O}$, respectively. ${ }^{41-43}$ The peaks at $284.9 \mathrm{eV}(\mathrm{C}-\mathrm{C} / \mathrm{C}=\mathrm{C}), 286.0 \mathrm{eV}(\mathrm{C}-\mathrm{O} / \mathrm{C}-\mathrm{N})$, and $288.7 \mathrm{eV}(\mathrm{O}-\mathrm{C}=\mathrm{O})$ can be also found in the $\mathrm{C}$ 1s XPS spectrum of the CDs-Thy (Fig. 3d). The N 1s spectrum (Fig. 3e) of the CDsPEI can be resolved two components which are attributed to C$\mathrm{NH}_{2}$ at $400.2 \mathrm{eV}$ and $\mathrm{C}=\mathrm{N}$ at $401.8 \mathrm{eV}$, respectively. However, the fitting analysis of the $\mathrm{N}$ 1s XPS spectrum of the CDs-Thy (Fig. 3f) reveals three distinct peaks at $399.6 \mathrm{eV}, 400.0 \mathrm{eV}$, and $401.9 \mathrm{eV}$ corresponding to $\mathrm{O}=\mathrm{C}-\mathrm{NH}, \mathrm{C}-\mathrm{N}-\mathrm{C}$ and $\mathrm{C}=\mathrm{N}$, respectively. It means that the primary amine of CDs-PEI almost totally translate to secondary amine after the reaction with thymine-1-acetic acid. Futhermore, the O 1s XPS spectra of the CDs-PEI (Fig. 3g) and the CDs-PEI (Fig. 3h) reveal two types of
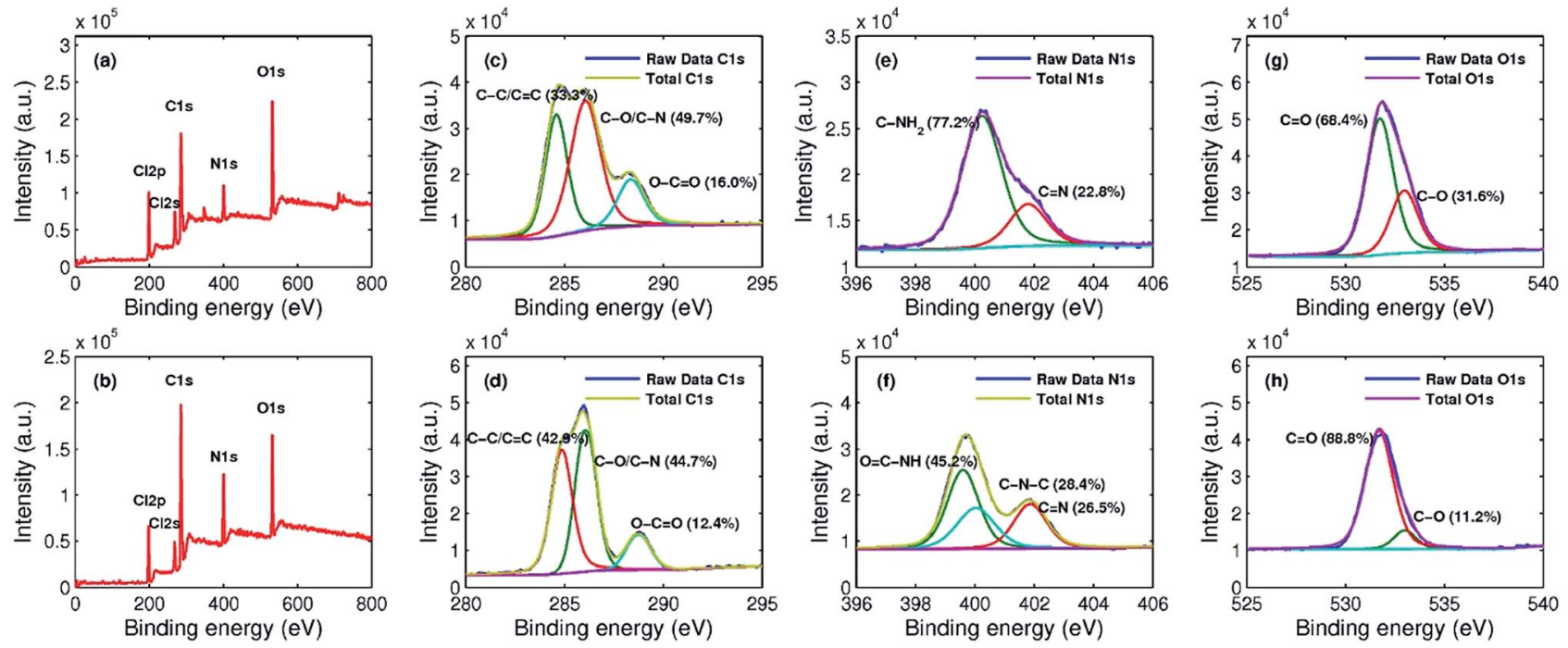

Fig. 3 (a) XPS survey of the CDs-PEI; (b) XPS survey of the CDs-Thy; (c) deconvoluted C 1s spectrum of CDs-PEl; (d) deconvoluted C 1s spectrum of the CDs-Thy; (e) deconvoluted N 1s spectrum of the CDs-PEl; ( $f$ ) deconvoluted N 1s spectrum of the CDs-Thy; (g) deconvoluted O 1s spectrum of the CDs-PEl; (h) deconvoluted $\mathrm{O}$ 1s spectrum of the CDs-Thy. 
oxygen bonds, which are associated with $\mathrm{C}=\mathrm{O}$ at $531.7 \mathrm{eV}$ and $\mathrm{C}-\mathrm{O}$ at $533.0 \mathrm{eV}$, respectively. ${ }^{44,45}$ And the relative contribution of $\mathrm{C}=\mathrm{O}$ in the CDs-Thy has an significant increase compared to the CDs-PEI, from $68.4 \%$ to $88.8 \%$. In conclusion, the results confirm that the surfaces of the CDs-PEI were successfully functionalized with thymine groups.

Fig. 4A and B show the TEM results of the CDs-PEI and the CDs-Thy, respectively. It can be found that the CDs-PEI mainly consist of uniform nanoparticles in size ranging from 2 to $5 \mathrm{~nm}$. The TEM showed that the average particle size of the CDs-PEI was about $3.0 \mathrm{~nm}$ (inset of Fig. 4A). In contrast, the particle size range and the average size of the CDs-Thy were 2-7 nm and $3.5 \mathrm{~nm}$ after the CDs-PEI modified with thymine group, respectively (inset of Fig. 4B). These results demonstrated that the conjugated thymine contributed about $0.5 \mathrm{~nm}$ to the average particle diameter.

Fig. 4C shows the UV/vis spectra of the CDs-Thy, the CDs-PEI and thymine-1-acetic acid, respectively. It can be seen that a relatively weak and broad absorption band appeared in a region from 320 to $400 \mathrm{~nm}$, which was ascribed to the $n-\pi^{*}$ transition of the $\mathrm{C}=\mathrm{O}$ and $\mathrm{C}=\mathrm{C}$ conjugated structure of both CDs-PEI and CDs-Thy. The strong absorption peak around
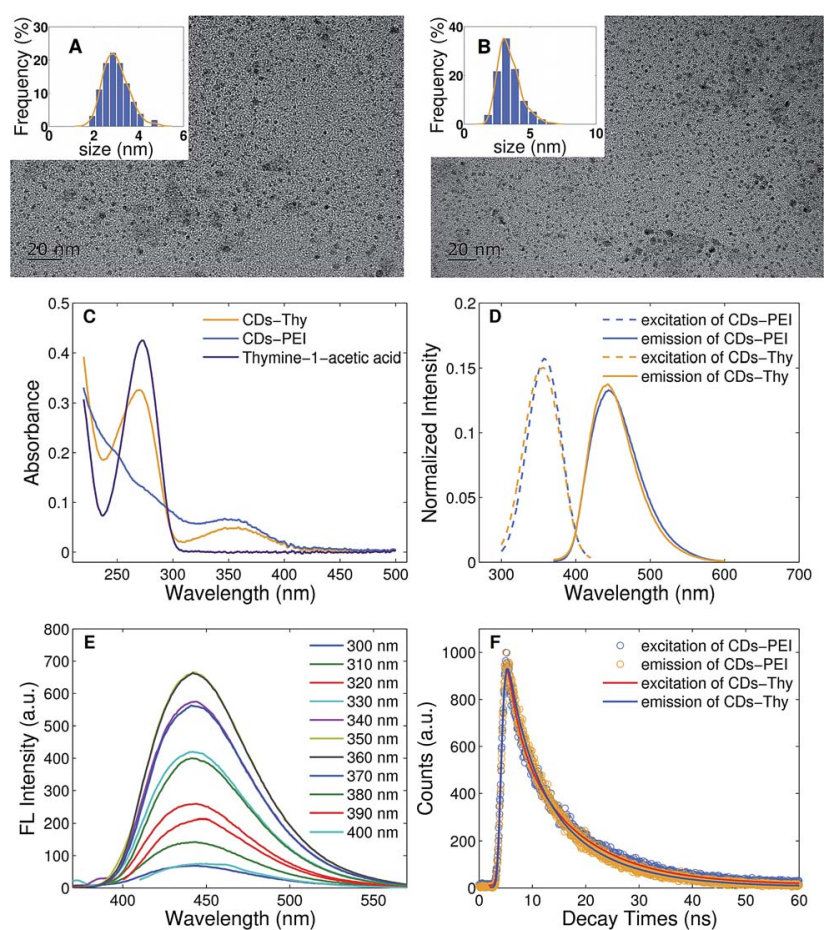

Fig. 4 (A) TEM images of CDs-PEI (inset: particle size distribution obtained from TEM image). (B) TEM images of CDs-Thy (inset: particle size distribution obtained from TEM image). (C) UV/vis absorption of CDs-PEI $\left(0.1 \mathrm{mg} \mathrm{mL}^{-1}\right)$, CDs-Thy $\left(0.1 \mathrm{mg} \mathrm{mL}^{-1}\right)$ and thymine-1-acetic acid $\left(8.3 \mu \mathrm{g} \mathrm{mL}^{-1}\right)$. (D) Normalized fluorescence excitation and emission spectra of CDs-PEI $\left(35.0 \mu \mathrm{g} \mathrm{mL}^{-1}\right)$ and CDs-Thy $\left(33.3 \mu \mathrm{g} \mathrm{mL}^{-1}\right)$. (E) Emission spectra of the CDs-Thy $\left(33.3 \mu \mathrm{g} \mathrm{mL}^{-1}\right)$ at different excitation wavelengths (300-400 nm). (F) Time decay profiles for CDs-PEI $\left(35.0 \mu \mathrm{g} \mathrm{mL}^{-1}\right.$ ) and CDs-Thy $\left(33.3 \mu \mathrm{g} \mathrm{mL}^{-1}\right.$ ) ( $\left.\lambda_{\text {ex }}: 354 \mathrm{~nm}\right)$. The line specifies the fitted curve while the scatter plots specify the experimental time decay profiles of both samples. All studies were performed in aqueous solution (0.2 M PBS buffer, $\mathrm{pH}$ 7.4).
$272 \mathrm{~nm}$ on the spectrum of CDs-Thy proved the successful modification of thymine group on the CDs because the similar peak was also observed in the spectrum of thymine-1-acetic acid. Furthermore, the content of thymine group was measured to be $6.35 \mu \mathrm{g}$ per $100 \mu \mathrm{g}$ by using the standard addition experiments (Fig. S1 $\dagger$ ).

Fig. 4D shows the fluorescence excitation and emission spectra of the CDs-PEI and the CDs-Thy, respectively. When excited at $354 \mathrm{~nm}$, both CDs-PEI and CDs-Thy exhibit maximum fluorescence emission around $440 \mathrm{~nm}$. However, the fluorescence emission spectra of CDs-PEI and CDs-Thy have no significant difference because of their same photoluminescence mechanism. Fig. 4E shows the emission spectra of the CDs-Thy at different excitation wavelengths which varied from $300 \mathrm{~nm}$ to $400 \mathrm{~nm}$. The emission of the CDs-Thy showed the excitationindependent property and may originated from a single species. ${ }^{46}$ Fig. $4 \mathrm{~F}$ shows the fluorescence decay spectra of CDsPEI and CDs-Thy. Both of the CDs-PEI and the CDs-Thy consists of a short $\tau_{1}$ and a long $\tau_{2}$ lifetime components (Table S1 $\dagger$ ). The fluorescence decay curves were fitted with a double-exponential function. ${ }^{47}$ The lifetime of CDs-Thy was 10.17 ns which was closed to the CDs-PEI (10.97 ns). Furthermore, the fluorescence quantum yields of CDs-PEI and CDs-

Table 1 Quantum yield of the fluorescent carbon dots

\begin{tabular}{lllll}
\hline Sample & $I$ & $A$ & $n$ & $Q$ \\
\hline Quinine sulfate & 44016 & 0.059 & 1.33 & $54.0 \%$ \\
CDs-PEI & 22827 & 0.070 & 1.33 & $23.6 \%$ \\
CDs-Thy & 28685 & 0.067 & 1.33 & $31.0 \%$
\end{tabular}
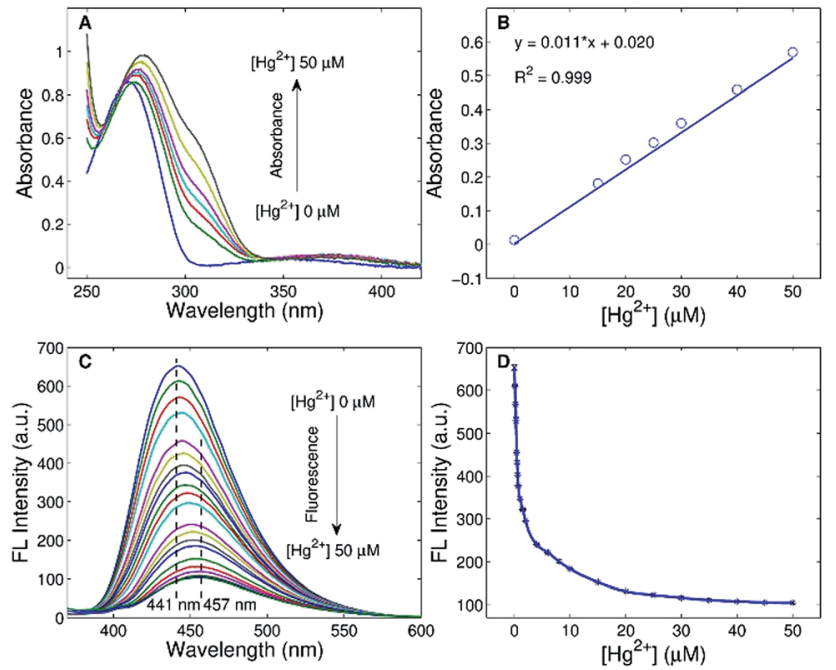

Fig. 5 (A) UV/vis spectrum of CDs-Thy $\left(0.1 \mathrm{mg} \mathrm{mL}^{-1}\right)$ in response to $\mathrm{Hg}^{2+}(0,15,20,25,30,40$, and $50 \mu \mathrm{M})$ in PBS solution (0.1 M, pH 7.4). (B) Linear regression equation of absorbance intensity at $307 \mathrm{~nm}$ of CDs-Thy $\left(0.1 \mathrm{mg} \mathrm{m}^{-1}\right)$ with the addition of $\mathrm{Hg}^{2+}(0,15,20,25,30,40$, and $50 \mu \mathrm{M})(0.1 \mathrm{M}$ PBS buffer, $\mathrm{pH}$ 7.4). (C) Fluorescence responses of the CDs-Thy $\left(33.3 \mu \mathrm{g} \mathrm{mL}^{-1}\right)$ in aqueous solution upon addition of $0 \mu \mathrm{M}$ to $50 \mu \mathrm{M} \mathrm{Hg}^{2+}$. (D) Fluorescence intensity of CDs-Thy $\left(33.3 \mu \mathrm{g} \mathrm{mL}^{-1}\right)$ in the presence of $0 \mu \mathrm{M}$ to $50 \mu \mathrm{M} \mathrm{Hg}^{2+}\left(\lambda_{\mathrm{ex}}=354 \mathrm{~nm}\right.$, slit: $\left.5 / 5 \mathrm{~nm}\right)$. 
Table 2 Comparison of different fluorescent sensors for $\mathrm{Hg}^{2+}$ ion detection

\begin{tabular}{llrl}
\hline $\begin{array}{l}\text { Fluorescent } \\
\text { sensor }\end{array}$ & $\begin{array}{l}\text { Linear range } \\
\left(\mathrm{mol} \mathrm{L}^{-1}\right)\end{array}$ & $\begin{array}{l}\text { Limit of } \\
\text { detection } \\
\left(\mathrm{mol} \mathrm{L}^{-1}\right)\end{array}$ & Ref. \\
\hline N-CDs & $2.5 \times 10^{-7}-6 \times 10^{-6}$ & $8 \times 10^{-8}$ & 48 \\
Polymer sensor & $1 \times 10^{-6}-3 \times 10^{-5}$ & $7.28 \times 10^{-7}$ & 49 \\
N-CDs-ssDNA & $1 \times 10^{-6}-6.5 \times 10^{-5}$ & $1.26 \times 10^{-6}$ & 50 \\
N-CDs & $0-2.5 \times 10^{-5}$ & $2.6 \times 10^{-7}$ & 51 \\
N,S-CDs & $0-4 \times 10^{-5}$ & $2 \times 10^{-6}$ & 34 \\
Thymine & $0-1.0 \times 10^{-6}$ & $3.5 \times 10^{-8}$ & This work \\
functionalized CDs & & &
\end{tabular}

Thy, referenced to a quinine sulfate solution in $0.1 \mathrm{M} \mathrm{H}_{2} \mathrm{SO}_{4}$ $\left(\Phi_{\mathrm{F}}=0.55\right)$, were determined to be $23.6 \%$ and $31.0 \%$, respectively (Table 1).

\section{2 $\mathrm{Hg}^{2+}$ sensing properties of the CDs-Thy}

Experimental conditions including $\mathrm{pH}$ and reaction time for $\mathrm{UV} / \mathrm{vis}$ and fluorescence experiments of the CDs-Thy were optimized (see Fig. S2†).

Fig. 5A shows the UV-vis spectra of the CDs-Thy in the presence of different concentrations of $\mathrm{Hg}^{2+}$. One can see that absorption peaks appeared around $307 \mathrm{~nm}$, which could be attributed to the evolution of $\mathrm{T}-\mathrm{Hg}^{2+}-\mathrm{T}$ structures. The intensities of the absorption band increased gradually with the increasing of
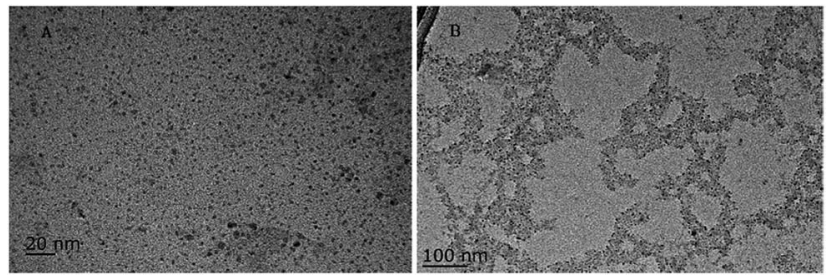

Fig. 6 (A) TEM image of the CDs-Thy $\left(33.3 \mu \mathrm{g} \mathrm{mL}^{-1}\right)$ without $\mathrm{Hg}^{2+}$. (B) TEM image of the CDs-Thy $\left(33.3 \mu \mathrm{g} \mathrm{mL}^{-1}\right)$ in the presence of $\mathrm{Hg}^{2+}$ $(20 \mu \mathrm{M})$.
$\mathrm{Hg}^{2+}$ concentrations. Fig. 5B shows a good linear relationship between the absorbance at $307 \mathrm{~nm}$ and the concentrations of $\mathrm{Hg}^{2+}$ with a correlation coefficient of $R^{2}=0.999$.

Fig. 5C shows the fluorescence emission response of the CDs-Thy reacting with increased concentrations of $\mathrm{Hg}^{2+}$ from 0.1 to $50 \mu \mathrm{M}$. One can find that the intensity at $440 \mathrm{~nm}$ was continuously decreased with the addition of $\mathrm{Hg}^{2+}$.

Fig. 5D shows a very steep decrease of fluorescence intensities at $441 \mathrm{~nm}$ when adding $\mathrm{Hg}^{2+}$ into the solution of the CDsThy. Such an outstanding fluorescence quenching was assigned to the photoinduced electron transfer from the excitation state of CDs-Thy to the vacant $\mathrm{d}$ orbital of $\mathrm{Hg}^{2+}$ when the $\mathrm{T}-\mathrm{Hg}^{2+}-\mathrm{T}$ structure was formed. ${ }^{34,36}$

Furthermore, the fluorescence intensity of the CDs-Thy toward $\mathrm{Hg}^{2+}$ decreased linearly over the $\mathrm{Hg}^{2+}$ concentration range of $0-1.0 \mu \mathrm{M}$ (Fig. S3†). The limit of detection (LOD) of the CDs-Thy for $\mathrm{Hg}^{2+}$ was thus determined to be about $3.5 \times$ $10^{-8} \mathrm{~mol} \mathrm{~L}^{-1}$ according to the formula: $\mathrm{LOD}=3 \sigma / k$, where the $\sigma$ means the standard deviation of the response, $k$ means the slope of the calibration curve. Table 2 shows the comparison of linear range and limit of detection with other recently reported $\mathrm{Hg}^{2+}$ probes. The CDs-Thy provide a remarkable lower detection limits and a satisfied linear range. These results indicated that the CDs-Thy are highly sensitive for $\mathrm{Hg}^{2+}$.

Fig. 6 shows the TEMs of the solutions of the CDs-Thy with and without $\mathrm{Hg}^{2+}$, respectively. One can find that large reticular aggregates were formed when $\mathrm{Hg}^{2+}$ was introduced to the solution of CDs-Thy (Fig. 6B). The quenching of the fluorescence emission by $\mathrm{Hg}^{2+}$ could be the photoinduced electron transfer (PET) process when the $\mathrm{T}-\mathrm{Hg}^{2+}-\mathrm{T}$ structures were formed.

\subsection{Selectivity and competition of CDs-Thy for $\mathbf{H g}^{2+}$ detection}

Fig. 7A shows the selectivity experiments of the CDs-Thy with 16 different metal cations. The fluorescence responses of the CDsThy were recorded in the presence of different metal cations, including $\mathrm{Cu}^{2+}, \mathrm{Hg}^{2+}, \mathrm{Zn}^{2+}, \mathrm{Mg}^{2+}, \mathrm{Fe}^{2+}, \mathrm{Au}^{3+}, \mathrm{Co}^{2+}, \mathrm{Ca}^{2+}, \mathrm{Pb}^{2+}$, $\mathrm{Ba}^{2+}, \mathrm{Cr}^{3+}, \mathrm{Na}^{+}, \mathrm{Ag}^{+}, \mathrm{Ni}^{2+}, \mathrm{K}^{+}$, and $\mathrm{Fe}^{3+}$. As expected, an outstanding fluorescence intensity descent was found only with
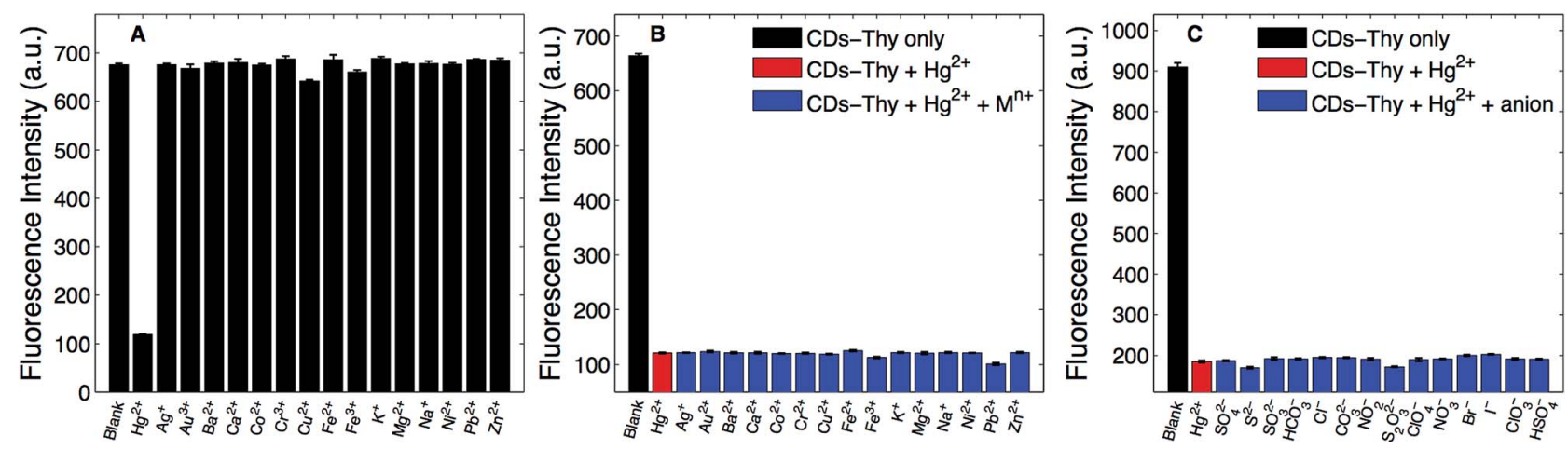

Fig. 7 (A) Selectivity of CDs-Thy $\left(33.3 \mu \mathrm{g} \mathrm{L}^{-1}\right)$ towards $\mathrm{Hg}^{2+}(30 \mu \mathrm{M})$ and other metal ions $(30 \mu \mathrm{M})$; (B) competitiveness of CDs-Thy ( $33.3 \mu \mathrm{g} \mathrm{L}^{-1}$ ) towards $\mathrm{Hg}^{2+}(30 \mu \mathrm{M})$ over other metal ions $(50 \mu \mathrm{M})$; (C) selectivity of CDs-Thy $\left(33.3 \mu \mathrm{g} \mathrm{L}^{-1}\right)$ towards $\mathrm{Hg}^{2+}(30 \mu \mathrm{M})$ in the presence of different anions $(50 \mu \mathrm{M})$. The fluorescence intensities at $441 \mathrm{~nm}$ were monitored in aqueous solution $(0.2 \mathrm{M}$ PBS buffer, $\mathrm{pH} 7.4)(\lambda \mathrm{ex}=354 \mathrm{~nm}$, slit: $5 / 5 \mathrm{~nm})$. 
Table 3 Determination of $\mathrm{Hg}^{2+}$ ion in tap water and river water $(n=3)$

\begin{tabular}{lllll}
\hline Samples & Spiked $[\mu \mathrm{M}]$ & Found $[\mu \mathrm{M}]$ & RSD [\%] & Recovery [\%] \\
\hline \multirow{2}{*}{ Tap water } & 0 & Not detected & - & - \\
& 0.50 & 0.52 & 2.26 & 104 \\
\multirow{4}{*}{ River water } & 0.75 & 0.77 & 0.94 & 102 \\
& 0.50 & Not detected & - & - \\
& 0.75 & 0.45 & 1.10 & 90 \\
& & 0.75 & 1.52 & 100 \\
\hline
\end{tabular}

the addition of $\mathrm{Hg}^{2+}$, while no noticeable changes in the fluorescence spectra were observed upon addition of other metal cations. These results demonstrated that the CDs-Thy possess a high selectivity for $\mathrm{Hg}^{2+}$ detection.

Competition measurements were also measured by adding the mixed solution of $\mathrm{Hg}^{2+}$ and other metal cations to the solution of CDs-Thy as shown in the Fig. 7B. Severe fluorescence quenching were observed when the CDs-Thy were exposed to $\mathrm{Hg}^{2+}$, which shows a superior reaction ability between the CDs-Thy and $\mathrm{Hg}^{2+}$. The fluorescence response experiments to $\mathrm{Hg}^{2+}$ of CDs-Thy in the presence of different anions including $\mathrm{SO}_{4}{ }^{2-}, \mathrm{S}^{2-}, \mathrm{SO}_{3}{ }^{2-}, \mathrm{HCO}_{3}{ }^{-}, \mathrm{Cl}^{-}, \mathrm{CO}_{3}{ }^{2-}, \mathrm{NO}_{2}{ }^{-}$, $\mathrm{S}_{2} \mathrm{O}_{3}{ }^{2-}, \mathrm{ClO}_{4}{ }^{-}, \mathrm{NO}_{3}{ }^{-}, \mathrm{Br}^{-}, \mathrm{I}^{-}, \mathrm{ClO}_{3}{ }^{-}$and $\mathrm{HSO}_{4}{ }^{-}$were also carried out as shown in the Fig. 7C. The fluorescence intensities of the CDs-Thy had no obvious change with the addition of $\mathrm{Hg}^{2+}$ even in the presence of different anions. The results indicate that the CDs-Thy exhibited high selectivity toward $\mathrm{Hg}^{2+}$.

\subsection{The analysis of water samples}

The CDs-Thy were applied in several tap water and river water samples to investigate the practicability of the CDs-Thy for $\mathrm{Hg}^{2+}$ sensing. Since no $\mathrm{Hg}^{2+}$ was detected in these samples, certain amount of standard $\mathrm{Hg}^{2+}$ was added to the raw water samples. The results (Table 3 ) shows that the recoveries ranged from $90 \%$ to $104 \%$, and the relative standard deviations are less than $7 \%$. These results verified that the analysis of $\mathrm{Hg}^{2+}$ using the CDs-Thy in water samples was satisfactory.

\section{Conclusions}

We developed a novel thymine-functionalized carbon dots, the CDs-Thy, which can be a useful tool for selective and sensitive determination of $\mathrm{Hg}^{2+}$ in a totally aqueous solution. The CDsThy showed a specific on-off fluorescence response to $\mathrm{Hg}^{2+}$ based on $\mathrm{T}-\mathrm{Hg}^{2+}-\mathrm{T}$ metal ion-mediated base pairs with a low detection limit. In addition, the CDs-Thy also had a rapid and selective response to $\mathrm{Hg}^{2+}$ at natural $\mathrm{pH}$ range. Moreover, the CDs-Thy also showed its ability for the measurement of $\mathrm{Hg}^{2+}$ in both tap and river water with satisfactory results. In view of these desirable features, the CDs-Thy could be a potential tool for detection and monitoring of $\mathrm{Hg}^{2+}$.

\section{Conflicts of interest}

There are no conflicts to declare.

\section{Acknowledgements}

This work was supported by the National Natural Science Foundation of China (20875106), Guangdong Natural Science Found Committee (9151027501000003), the Science and Technology Planning Project of Guangdong Province (2015A010105013), and the Science and Technology Planning Project of Guangzhou City (201607010349).

\section{References}

1 N. Basu, A. Scheuhammer, N. Grochowina, K. Klenavic, D. Evans, M. O'Brien and H. M. Chan, Environ. Sci. Technol., 2005, 39, 3585-3591.

2 D. W. Boening, Chemosphere, 2000, 40, 1335-1351.

3 P. Li, X. B. Feng, G. L. Qiu, L. H. Shang and Z. G. Li, J. Hazard. Mater., 2009, 168, 591-601.

4 A. Gupta, A. Chaudhary, P. Mehta, C. Dwivedi, S. Khan, N. C. Verma and C. K. Nandi, Chem. Commun., 2015, 51, 10750-10753.

5 T. W. Clarkson, Environ. Health Perspect., 2002, 110, 11-23.

6 T. W. Clarkson, L. Magos and G. J. Myers, N. Engl. J. Med., 2003, 349, 1731-1737.

7 P. Grandjean, P. Weihe, R. F. White and F. Debes, Environ. Res., 1998, 77, 165-172.

$8 \mathrm{~J}$. K. Virtanen, T. H. Rissanen, S. Voutilainen and T. P. Tuomainen, J. Nutr. Biochem., 2007, 18, 75-85.

9 E. M. Nolan and S. J. Lippard, Chem. Rev., 2008, 108, 34433480 .

10 Y. K. Yang, K. J. Yook, J. Tae, K. Jeong and Y. J. Tae, J. Am. Chem. Soc., 2005, 127, 16760-16761.

11 B.-C. Ye and B.-C. Yin, Angew. Chem., Int. Ed., 2008, 47, 83868389.

12 N. Wang, M. Lin, H. Dai and H. Ma, Biosens. Bioelectron., 2016, 79, 320-326.

13 K. P. Carter, A. M. Young and A. E. Palmer, Chem. Rev., 2014, 114, 4564-4601.

14 Y. Wang, F. Pan, Y. Zhang, F. Peng, Z. Huang, W. Zhang and W. Zhao, Analyst, 2016, 141, 4789-4795.

15 S. Lu, D. Wu, G. Li, Z. Lv, Z. Chen, L. Chen, G. Chen, L. Xia, J. You and Y. Wu, RSC Adv., 2016, 6, 103169-103177.

16 P. Kaewanan, P. Sricharoen, N. Limchoowong, T. Sripakdee, P. Nuengmatcha and S. Chanthai, RSC Adv., 2017, 7, 4805848067.

17 V. Jovanovski, N. I. Hrastnik and S. B. Hočevar, Electrochem. Commun., 2015, 57, 1-4.

18 M. Ghaedi, M. R. Fathi, A. Shokrollahi and F. Shajarat, Anal. Lett., 2006, 39, 1171-1185.

19 J. Allibone, E. Fatemian and P. J. Walker, J. Anal. At. Spectrom., 1999, 14, 235-239.

20 D. E. Nixon, M. F. Burritt and T. P. Moyer, J. Anal. Toxicol., 2007, 31, 281-287.

21 A. Zhao, Z. Chen, C. Zhao, N. Gao, J. Ren and X. Qu, Carbon, 2014, 85, 309-327.

22 S. N. Baker and G. a. Baker, Angew. Chem., Int. Ed., 2010, 49, 6726-6744. 
23 Y. Dong, J. Cai, X. You and Y. Chi, Analyst, 2015, 140, 74687486.

24 S. Qu, X. Wang, Q. Lu, X. Liu and L. Wang, Angew. Chem., 2012, 124, 12381-12384.

25 M. Havrdova, K. Hola, J. Skopalik, K. Tomankova, M. Petr, K. Cepe, K. Polakova, J. Tucek, A. B. Bourlinos and R. Zboril, Carbon, 2016, 99, 238-248.

26 A. Xiao, C. Wang, J. Chen, R. Guo, Z. Yan and J. Chen, Ecotoxicol. Environ. Saf., 2016, 133, 211-217.

27 F. R. Baptista, S. A. Belhout, S. Giordani and S. J. Quinn, Chem. Soc. Rev., 2015, 44, 4433-4453.

28 Y. Guo, L. Zhang, S. Zhang, Y. Yang, X. Chen and M. Zhang, Biosens. Bioelectron., 2015, 63, 61-71.

29 P. Li, X.-Y. Sun, J.-S. Shen and B. Liu, RSC Adv., 2016, 6, 61891-61896.

30 S. Liu, R. Liu, X. Xing, C. Yang, Y. Xu and D. Wu, RSC Adv., 2016, 6, 31884-31888.

31 Q. Li, Q. Huang, J.-J. Zhu, W.-G. Ji and Q.-X. Tong, RSC Adv., 2016, 6, 87230-87236.

32 C. Wang, D. Sun, Y. Chen and K. Zhuo, RSC Adv., 2016, 6, 86436-86442.

33 J. Yu, N. Song, Y.-K. Zhang, S.-X. Zhong, A.-J. Wang and J. Chen, Sens. Actuators, B, 2015, 214, 29-35.

34 L. Li, B. Yu and T. You, Biosens. Bioelectron., 2015, 74, 263269.

35 Y. Wang, S.-H. Kim and L. Feng, Anal. Chim. Acta, 2015, 890, 134-142.

36 J. He, H. Zhang, J. Zou, Y. Liu, J. Zhuang, Y. Xiao and B. Lei, Biosens. Bioelectron., 2016, 79, 531-535.
37 Y. Dong, R. Wang, H. Li, J. Shao, Y. Chi, X. Lin and G. Chen, Carbon, 2012, 50, 2810-2815.

38 Y. Dong, R. Wang, G. Li, C. Chen, Y. Chi and G. Chen, Anal. Chem., 2012, 84, 6220-6224.

39 A. Ono and H. Togashi, Angew. Chem., Int. Ed., 2004, 43, 4300-4302.

40 L. Li, Y. Wen, L. Xu, Q. Xu, S. Song, X. Zuo, J. Yan, W. Zhang and G. Liu, Biosens. Bioelectron., 2016, 75, 433-445.

41 B. Chen, F. Li, S. Li, W. Weng, H. Guo, T. Guo, X. Zhang, Y. Chen, T. Huang, X. Hong, et al., Nanoscale, 2013, 5, 1967.

42 S. Lu, G. Xiao, L. Sui, T. Feng, X. Yong, S. Zhu, B. Li, Z. Liu, B. Zou and M. Jin, Angew. Chem., Int. Ed., 2017, 56, 61876191.

43 Q. Huang, L. Zou and D. Chen, RSC Adv., 2016, 6, 8229482297.

44 Z. Yang, M. Xu, Y. Liu, F. He, F. Gao, Y. Su, H. Wei and Y. Zhang, Nanoscale, 2014, 6, 1890-1895.

45 J. Hou, J. Li, J. Sun, S. Ai and M. Wang, RSC Adv., 2014, 4, 37342.

46 D. Qu, M. Zheng, L. Zhang, H. Zhao, Z. Xie, X. Jing, R. E. Haddad, H. Fan and Z. Sun, Sci. Rep., 2014, 4, 1-9.

47 Y. Zhang, P. Cui, F. Zhang, X. Feng, Y. Wang, Y. Yang and X. Liu, Talanta, 2016, 152, 288-300.

48 L. Wang, B. Li, F. Xu, X. Shi, D. Feng, D. Wei, Y. Li, Y. Feng, Y. Wang, D. Jia, et al., Biosens. Bioelectron., 2016, 79, 1-8.

49 J. Li, Y. Wu, F. Song, G. Wei, Y. Cheng and C. Zhu, J. Mater. Chem., 2012, 22, 478-482.

50 Z. Li, Y. Ni and S. Kokot, Biosens. Bioelectron., 2015, 74, 91-97. 51 R. Zhang and W. Chen, Biosens. Bioelectron., 2014, 55, 83-90. 